\title{
Variasi Ungkapan Permohonan oleh Pembelajar Bahasa Jepang
}

\author{
THAMITA ISLAMI INDRASWARI*1, WISTRI MEISA ${ }^{2}$

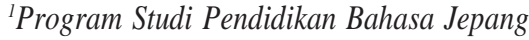 \\ Universitas Muhammadiyah Yogyakarta \\ thamita.indra@umy.ac.id
}

\begin{abstract}
ABSTRAK
Artikel ini berfokus pada variasi ungkapan permohonan dalam bahasa Jepang yang digunakan oleh pembelajar bahasa Jepang di Program Studi Pendidikan Bahasa Jepang Universitas Muhammadiyah Yogyakarta. Variasi bahasa dilihat dari segi ungkapan yang digunakan serta alur permohonan. Situasi pembicaraan adalah permohonan pada sensei dan permohonan pada senpai. Metode yang digunakan adalah metode kualitatif deskripstif dengan instrumen pengumpulan data berupa angket terbuka. Responden berjumlah 21 orang. Data dianalisis berdasarkan open coding model Strauss dan Corbin. Berdasarkan hasil analisis data, ditemukan bahwa untuk permohonan yang ditujukan pada sensei, pembelajar menggunakan dua belas variasi ungkapan, dan sepuluh variasi alur permohonan. Sementara itu, untuk permohonan yang ditujukan pada senpai, pembelajar menggunakan delapan variasi ungkapan dan sepuluh variasi alur permohonan.

Kata kunci : variasi bahasa, ungkapan permohonan, pembelajar bahasa Jepang
\end{abstract}

\begin{abstract}
This article examine language variation of irai hyogen used by the Japanese language learners of Japanese Language Education Department in Universitas Muhammadiyah Yogyakarta. In this study, language variations are focused in what expressions are being used as irai hyogen and how are the flow of expressions in two different settings, which is 1) irai hyogen being used by student to teacher, 2) irai hyogen being used by junior student (kohai) to senior student (senpai). The study employs qualitative-descriptive method with open-ended questionnaire as instrument, distributed to 21 people. The data are analyzed by using open coding model of Strauss and Corbin. The findings of the study showed that for irai hyogen expressed to sensei, there are twelve variations of irai hyogen and ten ways of expressing irai hyogen used by learners. Meanwhile for irai hyogen expressed to senpai it is found that learners use eight variations of irai hyogen and ten ways of expressing irai hyogen

Keywords : language variation, irai hyogen, Japanese language learner
\end{abstract}

\section{PENDAHULUAN}

Secara umum, bahasa dipandang sebagai alat komunikasi, yang diwujudkan dalam bentuk ungkapan bahasa, atau kalimatkalimat, baik dalam bentuk lisan maupun tulisan. Dalam konteks 
sosiolinguistik, bahasa dipandang sebagai suatu alat yang penggunaannya berhubungan dengan kepada siapa bahasa tersebut digunakan, kapan digunakan, dan untuk tujuan apa bahasa digunakan (Fishman, 1972 dalam Chaer, 2003:15). Maka, dapat ditemui variasi bahasa berdasarkan siapa yang berbicara, tempat atau situasi penggunaan bahasa, dan tujuan penggunaan bahasa Berdasarkan tujuan pengunaan, bahasa akan bervariasi sesuai dengan fungsi yang ditujunya; apakah fungsi emotif, direktif, fatik, atau denotatif. Ungkapan permohonan yang menjadi fokus penelitian ini merupakan ungkapan dengan fungsi direktif, digunakan untuk tujuan mengatur tingkah laku pendengar agar melakukan sesuatu, atau melakukan kegiatan sesuai dengan apa yang diinginkan oleh pembicara.

Pada buku pelajaran bahasa Jepang, selalu dijumpai pola kalimat yang digunakan untuk menyatakan permohonan, baik pada tingkat dasar, menengah, maupun tingkat atas. Dalam buku Minna no Nihongo Shokyu I dan Minna no Nihongo Shokyu II ditemukan materi pola kalimat untuk mengungkapkan permohonan, dengan penggunaan pola -te kudasai, -te itadakemasenka, te kudasaimasenka, -sasete itadakemasenka serta penggunaan kata onegaishimasu sebagai bentuk ungkapan permohonan. Sementara itu, pada buku Minna no Nihongo Chukyu I dan Chukyu II dijumpai pola te itadakenai deshouka, -te moraemasenka, -te moraenaideshouka, -sasete moraemasenka, -sasete moraenai deshouka, -sasete itadakenai deshohuka, serta onegai dekimasuka sebagai bentuk ungkapan permohonan.

Pembelajar biasanya diajari berbagai pola kalimat untuk menyatakan permohonan, dengan menggunakan pola-pola atau kosakata permohonan seperti yang diuraikan di atas. Tetapi apakah dengan diajarkannya pola kalimat yang bermacammacam, akan membuat pembelajar dapat menggunakan ungkapan yang bervariasi? Berdasarkan hasil survey awal oleh peneliti, diperoleh data seperti berikut:

Situasi 1

Anda mendengar ada informasi beasiswa di kampus. Anda 
ingin mendaftar beasiswa tersebut. Lalu, Anda ingin meminta tolong pada sensei menuliskan surat rekomendasi untuk mendaftar beasiswa

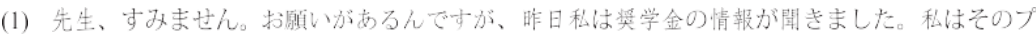

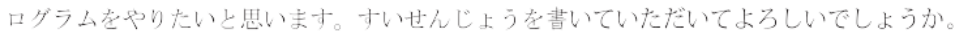

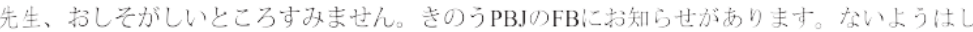

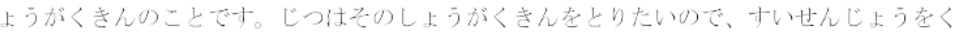
だざいまれか。ありがとうございます。

\section{Situasi 2}

Anda memiliki senpai yang akrab di kampus. Anda mendengar bahwa senpai tersebut pintar membuat sushi. Anda ingin diajari cara membuat sushi oleh senpai anda

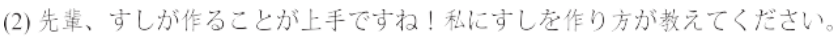

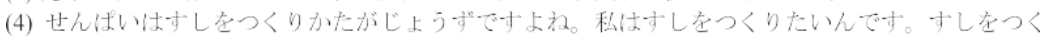
りかた老甫しえてもらえませんか。

Berdasarkan data (1), (2), (3), maupun (4) dapat terlihat bahwa pembelajar menggunakan tipe ungkapan yang berbeda menurut situasi (siapa yang diajak bicara). Ketika yang diajak bicara adalah sensei, pembelajar menggunakan ungkapan meminta tolong dengan dengan bentuk kaite itadaite yoroshii deshouka, dan suisenjou o kudasaimasenka. Alur permohonan yang dilakukan adalah pembuka pembicaraan (dengan mengungkapkan rasa penyesalan), dilanjutkan dengan uraian alasan diajukannya permohonan, lalu diakhiri dengan kalimat permohonan.

Sedangkan ketika yang diajak bicara adalah senpai, pembelajar menggunakan ungkapan oshiete kudasai dan oshiete moraemasenka. Alur permohonan dilakukan dengan dua cara. Cara pertama adalah dengan mengucapkan pembuka pembicaraan (pujian tentang senpai), diakhiri dengan kalimat permohonan. Cara kedua dilakukan dengan mengucapkan pembuka pembicaraan (pujian tentang senpai), dilanjutkan dengan uraian alasan diajukannya permohonan, lalu diakhiri dengan kalimat permohonan.

Dari temuan tersebut, dijumpai variasi register (tipe ungkapan maupun alur permohonan) yang digunakan ketika berbicara dalam situasi yang berbeda, seperti yang tampak pada penggunaan 
te itdaite yoroshii deshoukal -te kudasaimasenka kepada sensei, dan penggunaan te kudasai ketika berbicara pada senpai. Begitu pula dengan alur permohonan, dijumpai pergeseran alur permohonan dari pembuka $\rightarrow$ alasan $\rightarrow$ permohonan menjadi pembuka $\rightarrow$ permohonan. Karena itu peneliti tertarik untuk menggali lebih lanjut bagaimana variasi lain dari ungkapan permohonan yang digunakan oleh pembelajar bahasa Jepang, dengan rumusan masalah 1) Bagaimana variasi tipe ungkapan permohonan oleh pembelajar bahasa Jepang pada situasi yang berbeda?, 2) Bagaimana variasi alur permohonan yang dilakukan oleh pembelajar pada situasi yang berbeda?

\section{UNGKAPAN PERMOHONAN DALAM BAHASA JEPANG}

Ungkapan permohonan dalam bahasa Jepang, disebut dengan istilah irai hyougen. Irai hyougen merupakan ungkapan yang diucapkan pembicara agar pendengar melakukan sesuatu atau tidak melakukan sesuatu, demi keuntungan pembicara (Iori, dkk 2000:148). Dalam bahasa Jepang, ungkapan permohonan dapat diungkapkan dengan menggunakan bentuk -te dari kata kerja yang disertai kata kudasaru, morau, morau, moraeru, kureru, itadaku beserta bentuk variasinya, seperti -te itadaku yang ditambahkan deshouka menjadi pola -te itadakenai deshouka (Iori, dkk: 2000, Mizutani: 1991). Pada percakapan dalam situasi akrab, dapat digunakan ungkapan permohonan dengan bentuk -te dari kata kerja, tanpa dilekatkan dengan kata kudasaru, morau, morau, moraeru, kureru, itadaku seperti pada kalimat berikut:

Chotto matte (ne)

(Mizutani, 1991: 111)

Dijumpai pula ungkapan permohonan yang tidak menggunakan kudasaru, morau, morau, moraeru, kureru, itadaku, tetapi menggunakan kata onegaisuru maupun tanomu, bahkan menggunakan ungkapan yang sama sekali berbeda, seperti contoh kalimat berikut: 
Selain menggunakan pola-pola kalimat umum permohonan, alur permohonan juga merupakan hal yang perlu dipertimbangkan ketika mengajukan sebuah permohonan. Sebagaimana yang diungkapkan oleh Mizutani (1991), ketika membuat suatu permohonan, seseorang perlu mengekspresikan rasa menyesal karena sudah menyulitkan orang yang dimintai tolong. Setelah itu, permohonan diakhiri dengan kalimat yang tepat. Seperti pada contoh dialog berikut:

A: Sumimasen ga, chotto koko de matte ite itadakaemasenka. Chotto shigoto o katazukete kimasu node

B: Ee, douzo goyukkuri

(Mizutani, 1991: 108)

Dari contoh dialog di atas, dapat terlihat ekspresi rasa menyesal yang dinyatakan dengan kata sumimasen ( $\mathrm{ga}$ ), setelah itu muncul kalimat inti permohonan yang berupa koko de matte ite itadakaemasenka, lalu kalimat permohonan diakhiri dengan ungkapan yang menyatakan alasan diajukannya permohonan. Maka, dapat dipahami bahwa alur permohonan dianggap berterima jika memenuhi komponen berikut:

a. Ungkapan pembuka

b. Kalimat inti permohonan

c. Alasan dilakukannya permohonan

\section{METODE PENELITIAN}

Pada bagian ini, diuraikan mengenai metodologi yang meliputi pembahasan mengenai metode penelitian, sumber data, teknik pengumpulan data, serta teknik analisis data.

\section{A. METODE PENELITIAN}

Metode penelitian yang digunakan pada penelitian ini adalah metode kualitatif deskriptif, dengan tinjauan sosiolinguistik. Pada 
penelitian ini akan dideskripsikan variasi ungkapan permohonan yang digunakan oleh pembelajar bahasa Jepang, dengan parameter:

1) Situasi (latar belakang ungkapan permohonan, tujuan pembicaraan, kepada siapa ungkapan ditujukan)

2) Register yang digunakan (ungkapan permohonan, serta alur permohonan)

\section{B. SUMBER DATA}

Sumber data diperoleh dari responden, yaitu pembelajar bahasa Jepang yang merupakan mahasiswa Program Studi Pendidikan Bahasa Jepang Universitas Muhammadiyah Yogyakarta Tahun Ajaran 2017-2018. Responden berjumlah 21 orang dipilih dengan cara purposive sampling dengan kriteria utama sampling: telah diberikan materi kuliah tentang ungkapan permohonan dalam bahasa Jepang.

\section{TEKNIK PENGUMPULAN DATA}

Teknik pengumpulan data dilakukan dengan teknik catat, yaitu mencatat penggunaan bahasa oleh informan pada tabel data yang dilanjutkan dengan klasifikasi (Sudaryanto, 1993: 135). Instrumen yang digunakan berupa angket terbuka, yang didalamnya memuat petunjuk berupa: gambaran situasi serta petunjuk kosakata teknis yang berkaitan dengan situasi pembicaraan.

Pada penelitian ini, deskripsi situasi yang digunakan adalah:

1) Ungkapan permohonan yang ditujukan pada sensei, agar mahasiswa (pembicara) dibuatkan surat rekomendasi karena mahasiswa ingin melamar beasiswa

2) Ungkapan permohonan yang ditujukan pada senpai yang akrab, agar mahasiswa (pembicara) diajari cara membuat sushi, setelah mahasiswa mendengar kabar bahwa senpai tersebut terampil membuat sushi.

Responden diminta untuk menulis ungkapan permohonan yang akan digunakan berdasarkan deskripsi situasi yang tercantum dalam angket. 


\section{TEKNIK ANALISIS DATA}

Data yang diperoleh kemudian diolah dan dianalisis berdasarkan open coding model Strauss dan Corbin (1990:58) dalam Emzir (2012:137) dengan langkah-langkah berikut:

1) Pelabelan fenomena, dengan memberi label pada situasi dan penanda ungkapan permohonan dalam kalimat

2) Penemuan kategori-kategori, yaitu kategori situasi, kategori ungkapan, kategori alur permohonan

3) Penamaan kategori, dari temuan tiga kategori pada poin 2), maka dibuat penamaan kategori sebagai berikut:

a) Situasi Ungkapan

b) Tipe Penanda Ungkapan

c) Tipe Alur Permohonan

4) Pengembangan kategori, dari penamaan kategori pada poin 3) dikembangkan kategori baru, yaitu sub kategori dari tipe penanda ungkapan, dengan nama penanda ungkapan turunan

5) Penarikan simpulan

\section{HASIL PENELITIAN DAN PEMBAHASAN}

Berikut disajikan hasil analisis data. Data dibagi ke dalam kategori besar: situasi, kemunculan penanda ungkapan permohonan, dan tipe alur permohonan. Pada penelitian ini, digunakan dua situasi pembicaraan, yaitu:situasi permohonan terhadap sensei (Situasi 1) dan situasi permohonan terhadap senpai (Situasi 2). Berdasarkan hasil tabulasi data, didapatkan hasil sebagai berikut.

\section{A. VARIASI TIPE UNGKAPAN BERDASARKAN SITUASI 1) Variasi Ungkapan pada Situasi 1}

Pada situasi 1, dijumpai lima jenis penanda ungkapan permohonan, yaitu penanda berupa penggunaan kata itadaku, onegai, kudasaru, dekiru, moraeru. Dari msing-masing penanda ungkapan tersebut, ditemukan variasi ungkapan sebanyak 12 variasi seperti yang tampak pada tabel 1 di bawah.

Jenis ungkapan permohonan yang paling banyak digunakan 
adalah ungkapan dengan kata itadaku, khususnya dengan pola ungkapan --te itadakenai deshouka. Pada situasi ini, dijumpai pula variasi ungkapan oleh pembelajar yang berbeda dengan materi pada buku ajar, seperti yang tampak pada contoh kalimat (1), (13), dan (27). Pembelajar menambahkan register -yoroshii deshouka setelah penggunaan register itadaku.

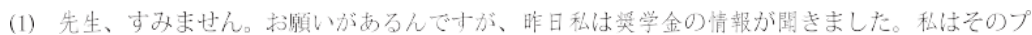

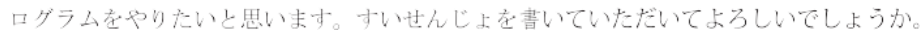

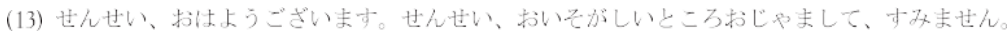

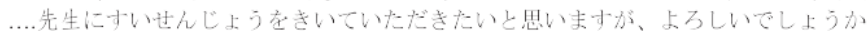

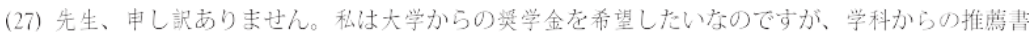

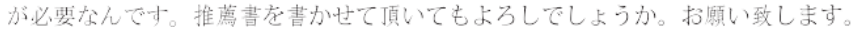

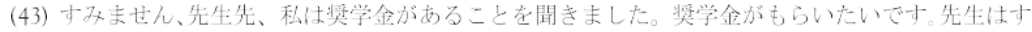
いせんじ上ら在菖くこと老いただいでいけないでしょうか。

\section{2) Variasi Ungkapan pada Situasi 2}

Pada situasi 2, dijumpai enam jenis penanda ungkapan permohonan, yaitu penanda berupa penggunaan kata itadaku, onegai, kudasaru, moraeru, kureru, dan morau. Dari masing-masing penanda ungkapan tersebut, ditemukan variasi ungkapan sebanyak delapan variasi seperti yang tampak pada tabel 2 di bawah.

Jenis ungkapan permohonan yang paling banyak digunakan adalah ungkapan dengan kata kudasaru dan moraeru, khususnya dengan pola ungkapan --te kudasai dan -te moraemasenka.

\section{B. VARIASI ALUR PERMOHONAN BERDASARKAN SITUASI \\ 1) Variasi Alur Permohonan pada Situasi 1}

Pada situasi 1, dijumpai sepuluh variasi alur permohonan, seperti yang tampak pada tabel 3 di bawah. Alur permohonan yang paling banyak digunakan adalah alur Tipe 2, yaitu pembuka (perasaan menyesal) - penjelasan alasan - ungkapan permohonan.

\section{2) Variasi Alur Permohonan pada Situasi 2}

Pada situasi 2, dijumpai sepuluh variasi alur permohonan, seperti yang tampak pada tabel 4 di bawah. Alur permohonan 
VOL. 2 N0. 1

TABEL 1

VARIASI UNGKAPAN PERMOHONAN PADA SITUASI 1

\begin{tabular}{|c|c|c|c|c|c|}
\hline $\begin{array}{l}\text { No. } \\
\text { Data }\end{array}$ & $\begin{array}{l}\text { Penanda } \\
\text { Ungkapan }\end{array}$ & $\begin{array}{l}\text { Kode Tipe } \\
\text { Penanda } \\
\text { Ungkapan }\end{array}$ & Ungkapan Turunan & $\begin{array}{l}\text { Kode Tipe } \\
\text { Ungkapan } \\
\text { Turunan }\end{array}$ & Contoh Kalimat \\
\hline 13 & いただく & 1 & 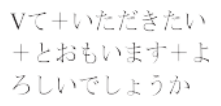 & $\mid-11$ & $\begin{array}{l}\text {.先生にすいせんじょうをきいていた } \\
\text { たきたいと思いますが、よろしいた } \\
\text { しょうか }\end{array}$ \\
\hline 23 & Wただく & 1 & $\begin{array}{l}\text { Vて+いたネけない } \\
\text { でしょ5か }\end{array}$ & $1-12$ & 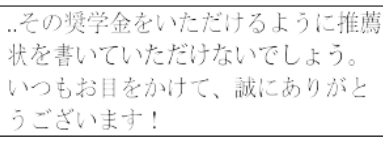 \\
\hline 29 & いただく & 1 & $\begin{array}{l}\text { Vさせて十いたたけ } \\
\text { ないでしょうか }\end{array}$ & $1-13$ & 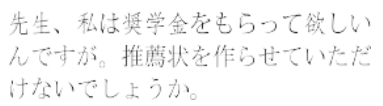 \\
\hline
\end{tabular}

\begin{tabular}{|c|c|c|c|c|}
\hline $39 \quad$ Wだ & 1 & $\begin{array}{l}\text { Vて十いただませ } \\
\text { んか }\end{array}$ & $\mid-14$ & 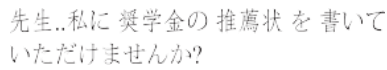 \\
\hline
\end{tabular}

\begin{tabular}{|c|c|c|c|c|c|}
\hline 43 & Wたた & 1 & $\begin{array}{l}\mathrm{N}+\text { 孛いただいて+ } \\
\text { いないでしょうか }\end{array}$ & $\mid-15$ & 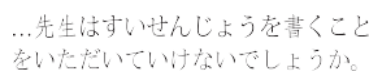 \\
\hline 27 & $\begin{array}{l}\text { Wただく、 } \\
\text { 执れる゙い }\end{array}$ & 2 & $\begin{array}{l}\text { Vさせて+いたたい } \\
\text { ても+よろしいてい } \\
\text { 上うか十枋极いし } \\
\text { ます }\end{array}$ & $\mid-21$ & 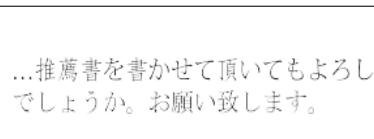 \\
\hline
\end{tabular}

\begin{tabular}{|c|c|c|c|c|c|}
\hline 17 & お极がい & 3 & 术极扔い & $0-31$ & 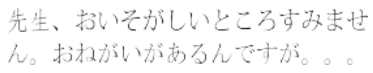 \\
\hline
\end{tabular}

\begin{tabular}{|c|c|c|c|c|c|}
\hline 1 & $\begin{array}{l}\text { 抒ねだい、 } \\
\text { Wただく }\end{array}$ & 4 & $\begin{array}{l}\text { お极い+Vて+い } \\
\text { ただいて+ようしい } \\
\text { だしょうか }\end{array}$ & $0-41$ & $\begin{array}{l}\text { 导いせんじょ者いていただいて } \\
\text { よろしいでしょうか。 }\end{array}$ \\
\hline 3 & $\begin{array}{l}\text { 执肪い, } \\
\text { Wだく }\end{array}$ & 4 & $\begin{array}{l}\text { 极がい+Vて+い } \\
\text { ただけないでしょう } \\
\text { か }\end{array}$ & $0-42$ & 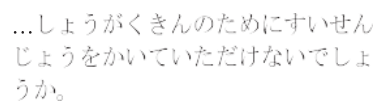 \\
\hline 21 & くださる & 5 & $\begin{array}{l}\mathrm{N}+\text { tくたざいせ } \\
\text { んか }\end{array}$ & $K-51$ & $\begin{array}{l}\text { ‥すすいせんじょうたくださいませ } \\
\text { んか。ありがとうございま寸。 }\end{array}$ \\
\hline
\end{tabular}

\begin{tabular}{|c|c|c|c|c|c|}
\hline 7 & セさる & 6 & 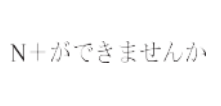 & D-61 & 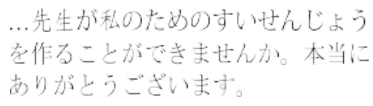 \\
\hline 25 & むらえる & 7 & $\begin{array}{l}\text { Vさせて十もらえま } \\
\text { せんか }\end{array}$ & $M-71$ & $\begin{array}{l}\text { 先生、すみません。奨学金のために } \\
\text { 推萀状を書かせてもらえませんか。 }\end{array}$ \\
\hline
\end{tabular}


TABEL 2

VARIASI UNGKAPAN PERMOHONAN PADA SITUASI 2

\begin{tabular}{|c|c|c|c|c|c|}
\hline $\begin{array}{l}\text { No. } \\
\text { Data }\end{array}$ & $\begin{array}{l}\text { Penanda } \\
\text { Ungkapan }\end{array}$ & $\begin{array}{l}\text { Kode Tipe } \\
\text { Penanda } \\
\text { Ungkapan }\end{array}$ & Ungkapan Turunan & $\begin{array}{l}\text { Kode Tipe } \\
\text { Ungkapan } \\
\text { Turunan }\end{array}$ & Contoh Kalimat \\
\hline 2 & くださる & 5 & Vてください & $K-52$ & $\begin{array}{l}\text { 先辈、すしが作ることが上乎です } \\
\text { わ！私にすしをつくり方がおしえて } \\
\text { ください。 }\end{array}$ \\
\hline 8 & 找极加い & 3 & 抒极がいしま寸 & $0-32$ & 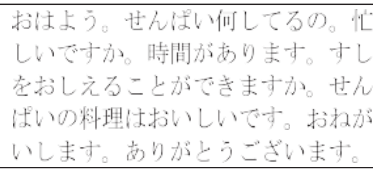 \\
\hline 18 & むらえる & 7 & Vて古らえ东せんわ & $M-72$ & $\begin{array}{l}\text { せんばい、すしの作り方をおしえて } \\
\text { もらえませんか。 }\end{array}$ \\
\hline 26 & くれる & 8 & Vてくれませんわ & $K-81$ & $\begin{array}{l}\text { 先神、寸しの作り方在教えてくれま } \\
\text { せんか。 }\end{array}$ \\
\hline 32 & 拐极力代い & 3 & Vて扩ねがしま寸 & $0-33$ & $\begin{array}{l}\text { 先輩、このすしを作り方が教えて } \\
\text { 覑いします。 }\end{array}$ \\
\hline 36 & $\begin{array}{l}\text { くえる、も } \\
ら え る\end{array}$ & 9 & $\begin{array}{l}\text { Vてくれで+もらえ } \\
\text { ない+でしょ5か }\end{array}$ & K-91 & $\begin{array}{l}\text { 先輩、すし老作ってが教えてくれて } \\
\text { むらないていうか。 }\end{array}$ \\
\hline 42 & 555 & 10 & $\begin{array}{l}\text { Vてむらってもいい } \\
\text { ですか }\end{array}$ & M-101 & 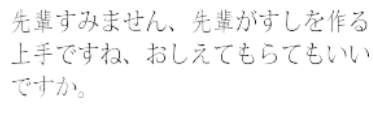 \\
\hline 46 & いただく & 1 & $\begin{array}{l}\text { Vて+いただけませ } \\
\text { んか }\end{array}$ & $\mathrm{I}-14$ & $\begin{array}{l}\text { Senpai, sushi no tsukurikata wo oshiete } \\
\text { itadakemasenka. }\end{array}$ \\
\hline
\end{tabular}

yang paling banyak digunakan adalah alur Tipe 19, yaitu permohonan yang langsung diucapkan tanpa ada pembuka maupun penjelasan alasan dilakukannya permohonan.

\section{SIMPULAN DAN SARAN}

Berdasarkan hasil analisis data, maka pada penelitian ini dapat disampaikan simpulan dan saran sebagai berikut. 
TABEL 3

VARIASI ALUR PERMOHONAN PADA SITUASI 1

\begin{tabular}{|c|c|c|c|}
\hline $\begin{array}{l}\text { No. } \\
\text { Data }\end{array}$ & Contoh Kalimat & Alur & $\begin{array}{l}\text { Kode } \\
\text { Tipe } \\
\text { Alur }\end{array}$ \\
\hline 15 & 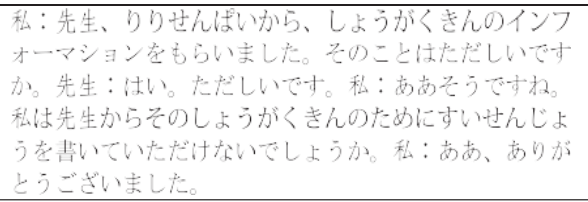 & $\begin{array}{l}\text { pembuka (konfirmasi informasi) - } \\
\text { penjelasan alasan - ungkapan } \\
\text { permohonan }\end{array}$ & 1 \\
\hline 13 & 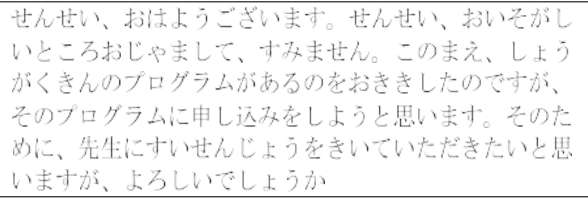 & $\begin{array}{l}\text { pembuka (perasaan menyesal) - } \\
\text { penjelasan alasan - ungkapan } \\
\text { permohonan }\end{array}$ & 2 \\
\hline 7 & 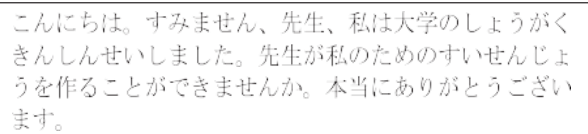 & $\begin{array}{l}\text { pembuka (perasaan menyesal) - } \\
\text { penjelasan alasan - ungkapan } \\
\text { permohonan - ungkapan terima } \\
\text { kasih }\end{array}$ & 3 \\
\hline 25 & $\begin{array}{l}\text { 先生、す孙ません。奨学金のために推篤状在青かせても } \\
\text { らえませんか。 }\end{array}$ & $\begin{array}{l}\text { pembuka (perasaan menyesal) - } \\
\text { ungkapan permohonan }\end{array}$ & 4 \\
\hline 17 & 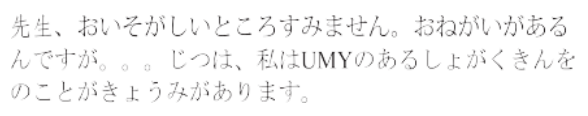 & $\begin{array}{l}\text { pembuka (perasaan menyesal) - } \\
\text { ungkapan permohonan - } \\
\text { penjelasan alasan }\end{array}$ & 5 \\
\hline 9 & 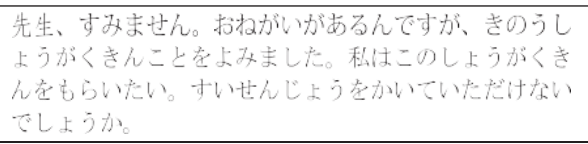 & $\begin{array}{l}\text { pembuka (perasaan menyesal) - } \\
\text { ungkapan permohonan - } \\
\text { penjelasan alasan - ungkapan } \\
\text { permohonan }\end{array}$ & 6 \\
\hline 3 & 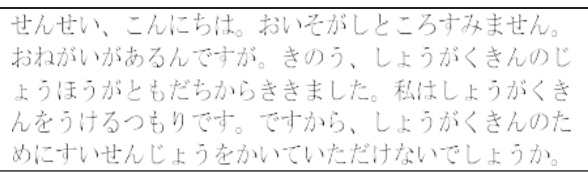 & $\begin{array}{l}\text { pembuka (perasaan menyesal) - } \\
\text { ungkapan permohonan langsung }\end{array}$ & 7 \\
\hline 1 & 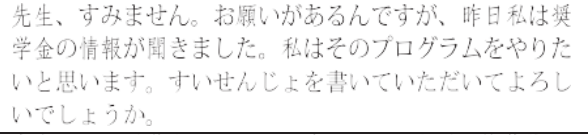 & $\begin{array}{l}\text { Pembuka (perasaan menyesal)- } \\
\text { ungkapan permohonan langsung- } \\
\text { penjelasan alasan-ungkapan } \\
\text { permohonan langsung }\end{array}$ & 8 \\
\hline 29 & 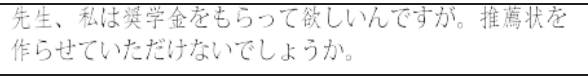 & $\begin{array}{l}\text { penjelasan alasan - ungkapan } \\
\text { permohonan }\end{array}$ & 9 \\
\hline 37 & 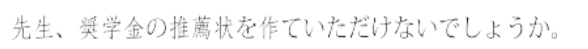 & ungkapan permohonan & 10 \\
\hline
\end{tabular}


TABEL 4

VARIASI ALUR PERMOHONAN PADA SITUASI 2

\begin{tabular}{|c|c|c|c|}
\hline No. Data & Contoh Kalimat & Alur & $\begin{array}{l}\text { Kode } \\
\text { Tipe } \\
\text { Alur }\end{array}$ \\
\hline 16 & 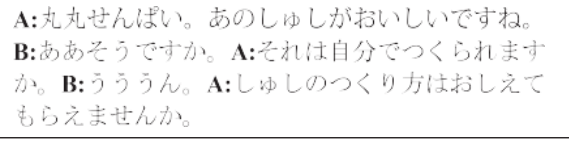 & $\begin{array}{l}\text { pembuka (basa-basi) - } \\
\text { ungkapan } \\
\text { permohonan }\end{array}$ & 11 \\
\hline 20 & 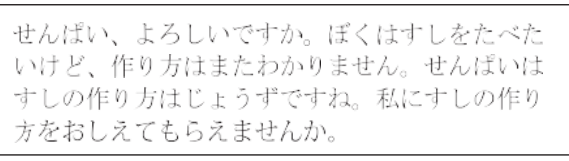 & $\begin{array}{l}\text { pembuka (basa-basi) - } \\
\text { penjelasan alasan - } \\
\text { konfirmasi informasi - } \\
\text { ungkapan } \\
\text { permohonan }\end{array}$ & 12 \\
\hline 8 & 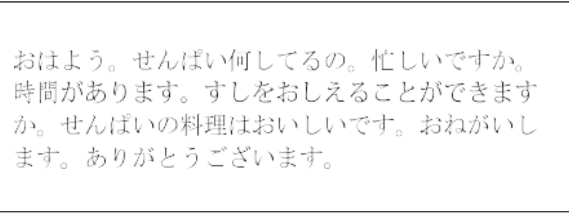 & $\begin{array}{l}\text { pembuka (basa-basi) - } \\
\text { ungkapan } \\
\text { permohonan - } \\
\text { penjelasan alasan } \\
\text { (pujian) - ungkapan } \\
\text { permohonan - } \\
\text { ungkapan terima kasih }\end{array}$ & 13 \\
\hline 42 & $\begin{array}{l}\text { 先輩す多ません、先輩がすしを作る上乎ですね、 } \\
\text { おしえてもらてもいいです。 }\end{array}$ & $\begin{array}{l}\text { pembuka (perasaan } \\
\text { menyesal) - pujian - } \\
\text { ungkapan } \\
\text { permohonan }\end{array}$ & 14 \\
\hline 4 & 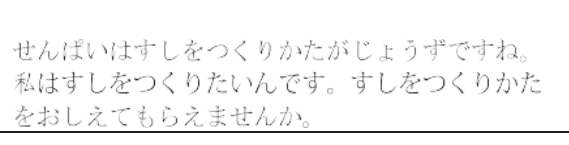 & $\begin{array}{l}\text { pembuka (pujian) - } \\
\text { penjelasan alasan - } \\
\text { ungkapan } \\
\text { permohonan }\end{array}$ & 15 \\
\hline 2 & $\begin{array}{l}\text { 先輩、すしが作ることが上乎です极! 私にすしを } \\
\text { つくり方が扰しえてください。 }\end{array}$ & $\begin{array}{l}\text { pembuka (pujian) - } \\
\text { ungkapan } \\
\text { permohonan }\end{array}$ & 16 \\
\hline 40 & 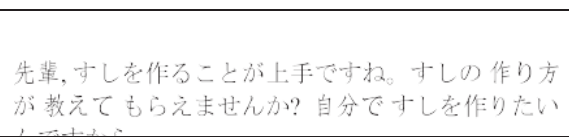 & $\begin{array}{l}\text { pembuka (pujian) - } \\
\text { ungkapan } \\
\text { permohonan - } \\
\text { penjelasan alasan }\end{array}$ & 17 \\
\hline 28 & $\begin{array}{l}\text { 先輩、寿司の作り方が上乎んだって。私に教えて } \\
\text { ください。 }\end{array}$ & $\begin{array}{l}\text { pembuka (konfirmasi } \\
\text { informasi) - penjelasan } \\
\text { alasan - ungkapan } \\
\text { permohonan }\end{array}$ & 1 \\
\hline 14 & 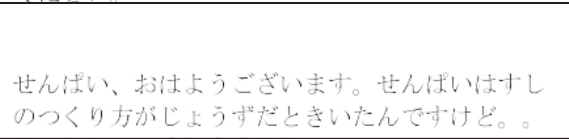 & $\begin{array}{l}\text { pembuka (salam) - } \\
\text { konfirmasi informasi - } \\
\text { ungkapan } \\
\text { permohonan }\end{array}$ & 18 \\
\hline 18 & $\begin{array}{l}\text { 私におしえてくれませんか。 } \\
\text { せんばい、すしの作り方をおしえてもらえません } \\
\text { か。 }\end{array}$ & $\begin{array}{l}\text { ungkapan } \\
\text { permohonan }\end{array}$ & 19 \\
\hline
\end{tabular}




\section{A. SIMPULAN}

\section{1) Variasi Ungkapan}

Dari segi variasi tipe ungkapan permohonan dalam bahasa Jepang yang digunakan oleh pembelajar, dapat dipahami bahwa:

a) pembelajar menggunakan register (kata) yang sama untuk melakukan permohonan meskipun berada dalam situasi yang berbeda

b) register irai hyogen yang umum digunakan pembelajar adalah: -onegai ga arundesuga, onegaishimasu, -te onegaishimasu, -te itadaku, -te itadakemasenka, -sasete itadakenai deshouka, -itadakenai deshouka. -te itadakitai, -te itadakemasenka, -sasete moraemasenka, -te moraenai deshouka, -moratte mo iidesuka -te moraemasenka, kudasaimasenka, -te kudasai, -te kuremasenka, -koto ga dekimasuka, -dekimasenka

c) register kata permohonan yang sama-sama ditemui pada kedua situasi adalah: itadaku, onegai(suru), kudasaru, moraeru. Tetapi variasi dari register tersebut berbeda berdasarkan situasi.

d) untuk permohonan yang ditujukan pada sensei, register berupa kata permohonan yang digunakan hanya berjumlah lima register, yaitu: register dasar dekiru, itadaku, onegai(suru), kudasaru, moraeru. Tetapi, pembelajar menggunakan ungkapan yang bervariasi, yang diturunkan dari kelima register tersebut. Contohnya penggunaan register itadaku yang digabung dengan onegai(suru). Pada situasi ini, ditemukan dua belas variasi ungkapan permohonan yang digunakan oleh pembelajar.

e) untuk permohonan yang ditujukan pada senpai, register berupa kata permohonan yang digunakan berjumlah enam, yaitu register dasar itadaku, onegai(suru), kudasaru, kureru, morau, moraeru. Tetapi, dari keenam register tersebut, hanya ditemukan delapan variasi ungkapan yang digunakan oleh pembelajar.

\section{2) Alur Permohonan}

Dari segi variasi tipe alur permohonan, dapat dipahami bahwa:

a) Secara umum, alur permohonan yang digunakan oleh pem- 
belajar telah memenuhi komponen minimal berupa ungkapan pembuka, kalimat inti permohonan, serta penjelasan alasan diajukannya permohonan.

b) Pada permohonan yang diajukan pada sensei ditemukan dua tipe alur (tipe 9 dan tipe 10) yang digunakan pembelajar yang tidak memenuhi komponen ungkapan pembuka. Pembelajar langsung mengutarakan kalimat inti permohonan dan penjelasan alasan permohonan

c) Alur permohonan tipe 1: pembuka (konfirmasi informasi) penjelasan alasan - ungkapan permohonan, digunakan oleh pembelajar baik dalam situasi permohonan kepada sensei maupun kepada senpai.

d) ketika pembelajar berbicara pada sensei, pembelajar cenderung menyampaikan permohonan dengan cara menyampaikan pembuka (dengan mengungkapkan perasaan menyesal), dilanjutkan dengan penjelasan alasan dan diakhiri dengan ungkapan permohonan.

e) ketika pembelajar berbicara pada senpai, cara yang banyak digunakan adalah langsung menyampaikan ungkapan permohonan tanpa diawali oleh pembuka maupun penjelasan alasan dilakukannya permohonan.

f) ditemukan kecederungan pembelajar menggunakan ungkapan pembuka berupa pernyatan ungkapan penyesalan (karena akan merepotkan sensei), sedangkan ketika berbicara dengan senpai pembicara lebih cenderung menggunakan ungkapan pembuka berupa pernyataan pujian atas kemampuan senpai.

\section{B. SARAN}

\section{1) Pemanfaatan Hasil Penelitian}

Berdasarkan hasil temuan data kalimat, pengajar dapat mengidentifikasi penggunaan ungkapan mana dari pembelajar yang kurang berterima, dengan membandingkan antara variasi bahasa yang muncul dengan tuntunan gramatika maupun tuntunan penggunaan bahasa Jepang secara pragmatis. Berdasarkan hasil bandingan ini, pengajar dapat menyusun: 
a) Poin-poin gramatika (pemilihan kata, pola kalimat) mana yang sebaiknya perlu diberikan perhatian khusus ketika mengajarkan ungkapan permohonan dalam bahasa Jepang

b) strategi mengajarkan pola kalimat maupun ungkapan bahasa Jepang untuk menghindari kesalahan penggunaan ungkapan permohonan di kemudian hari

\section{2) Pengembangan Penelitian}

Pada penelitian ini, variasi bahasa hanya dilihat dari bentuk ungkapan dan alur permohonan oleh pembelajar kepada sensei dan senpai, dengan konten permohonan yang berbeda. Untuk selanjutnya, dapat diteliti mengenai bagaimana pergeseran register dari segi bentuk ungkapan maupun alur permohonan oleh pembelajar ketika mengajukan konten permohonan yang sama, tetapi ditujukan pada pendengar yang berbeda.

\section{DAFTAR PUSTAKA}

Emzir. (2012). Metodologi Penelitian Kualitatif Analisis Data. Jakarta: Rajawali Press Chaer, Abdul. (2004). Sosiolinguistik Perkenalan Awal. Jakarta: Rineka Cipta Iori Isao. (2000). Shoukyuu o Oshieru Hito no Tame no Nihongo Bunpou Handobukku. Tokyo: 3A Corporation Mizutani Osamu dan Mizutani Nobuko. (1991). How to Be Polite in Japanese. Tokyo: The Japan Times

Sudaryanto. (1993). Metode dan Aneka Teknik Analisis Bahasa. Yogyakarta: Duta Wacana University Press

Wray, Alison dkk. (1998). Projects in Linguistics. London: Arnold

3A Network. (2008). Minna no Nihongo Chukyu I. Tokyo: 3A Corporation . (2012). Minna no Nihongo Chukyu II. Tokyo: 3A Corporation . (2009). Minna no Nihongo Shokyu I. Surabaya: IMAF Press . (2000). Minna no Nihongo Shokyu I Terjemahan dan Keterangan Tata Bahasa.

Tokyo: 3A Corporation . (2008). Minna no Nihongo Shokyu II. Surabaya: IMAF Press 